\title{
РЕАЛИЗАЦИЯ ПРОГРАММ РАЗВИТИЯ ВУЗОВ НА ОСНОВЕ ПРОЕКТНОГО УПРАВЛЕНИЯ
}

\section{REALIZATION OF HIGHER EDUCATIONAL INSTITUTIONS DEVELOPMENT PROGRAMS BASED ON PROJECT MANAGEMENT}

\section{Sandler \\ D. Ostrovkin}

Summary: The article is devoted to the formation of programs for the development of Russian universities in accordance with the urgent tasks facing the Russian higher education. The development programs of the leading universities of the Russian Federation included in the "Project 5-100" program have been analyzed and the main projects implemented by these universities also have been identified and analyzed. On the basis of the collected data and the analysis which was carried out, recommendations were formulated for the universal part of development programs, including composition of the main projects. Approaches to program management based on project management tools have been formulated. They will allow to conduct a comprehensive modernization of all components of the university's activities. The approaches provide the economic viability and integrity of the development of the university.

Keywords: project management, management, university, higher education, university development programs, university modernization, university management.
$\mathrm{B}$ последние несколько десятилетий российское высшее образование находится в состоянии перманентных реформ и изменений. Его модернизация, в первую очередь, связана с трансформацией социально-экономических условий, совершенствованием образовательных технологий и программ, формированием новых подходов к образовательной среде. Однако немаловажным условием этих изменений становится поиск новых подходов к процессу управления университетами, позволяющих повысить его эффективность. Этому способствуют и цели, сформулированные в приоритетных национальных проектах. Так, в соответствии с национальным проектом «Образование», Россия должна войти в число мировых стран-лидеров по качеству образования, в результате чего будет обеспечена его глобальная конкурентоспособность [1].

Кроме того, в июне 2020 г. Министерство науки и высшего образования представило проект «Программы стратегического академического лидерства» [2]. Она будет определять вектор развития российской высшей школы на ближайшее десятилетие. В основе Стратегии
Сандлер Даниил Геннадьевич

К.э.н., дочент, ФГАОУ ВО «УрФУ имени первого Президента

России Б.Н. Ельцина»

d.g.sandler@urfu.ru

Островкин Денис Леонидович

К.и.н., ФГБОУ ВО «Уральский государственный лесотехнический университет» ostrovkin.denis@yandex.ru

Аннотация: (татья посвящена вопросам формирования программ развития российских вузов в соответствии с актуальными задачами, которые стоят перед отечественным высшим образованием. Проанализированы программы развития ведущих вузов Российской Федерации, входящих в программу «Проект 5-100», выявлены и проанализированы основные проекты, реализуемые данными университетами. На основе собранных данных и проведенного анализа были сформулированы рекомендации по универсальной части программ развития, в том числе состав основных проектов. Сформулированы подходы к управлению программой на основе инструментов проектного управления, которые позволят проводить комплексную модернизацию всех составляющих направлений деятельности университета. Подходы предусматривают экономическую состоятельность и целостность развития вуза.

Ключевые слова: проектное управление, менеджмент, университет, высшее образование, программы развития вузов, модернизации университета, управление университетом.

лежит идея, которая основывается на базисном значении высшего образования и науки для достижения конкретных результатов и национальных целей, выразившихся в указе Президента РФ от 7 мая 2018 года.

В соответствии с концепцией можно выделить две главные идеи. Во-первых, что именно университеты должны готовить качественных специалистов, которые в последующем будут востребованы на рынке труда и иметь потенциал для качественных изменений в экономике. Во-вторых, вузы должны стать центром науки и научных исследований, проводить современные разработки опираясь на требования рынка и региональные потребности. Наконец, в-третьих, именно вузы-лидеры должны взять на себя функцию быть во главе развития регионов.

Достижение данной цели подталкивает руководителей вузов обращаться не только к воспроизведению стандартных управленческих рецептов и компетенций, а к поиску «уникальных конкретных преимуществ и продуктов». При этом получение его невозможно путем из- 
вестного воспроизведения управленческих действий. В связи с этим, все чаще руководители вузов обращаются к проектному управлению.

В современной литературе, при различных дискуссиях, не редко два различных понятия - «проектное управление» и «проектное обучение» - используют как инструменты для решения сходных задач. Однако, по нашему мнению, несмотря на сходную инструментальную основу, они применяются в разных процессах и имеют различную область применения. Считаем необходимым подчеркнуть различия в вышеназванных понятиях. Так, под «проектным управлением» мы подразумеваем процесс управления деятельностью, нацеленной на разработку и реализацию проектов [3], а под «проектным обучением» - базовую образовательную технологию, поддерживающую компетентностно-ориентированный подход в образовании [4]. Важность внедрения проектного обучения для решения стратегических задач не является отдельным предметом данной статьи и раскрыта в целом ряде работ $[5,6,7,8]$

Насколько проектное управление свойственно вузам, возможно ли его внедрение на постоянную основу и каковы его параметры? Данные теоретические подходы к построению проектного управления в университетах в настоящее время освещены достаточно большим количеством авторов в научной литературе [9, 10, 11, 12]. Суммировав, выделим ряд приоритетных черт, имеющихся у проектного подхода, по мнению исследователей:

- объединение различных областей и сфер жизнедеятельности университета для решения конкретной стратегической задачи, а также возможность гибкого изменения в соответствии с меняющейся средой;

- возможность получить результат за ограниченное время и оценить его действие;

- создание проектных команд из числа сотрудников различной подчиненности, а также гибкость таких структур;

- поощрение и стимулирование мотивации сотрудников (как личной, так и командной) в соответствии с выполненной задачей;

- усиление роли руководителя проекта и личной ответственности за его выполнение $[12,13]$.

Кроме того, для урегулирования процессов и выработки общих подходов к управлению проектами в 2011 г. Федеральным агентством по техническому регулированию и метрологии были приняты стандарты ГОСТ Р 54869-2011 «Проектный менеджмент. Требования к управлению проектом», ГОСТ Р 54870-2011 «Проектный менеджмент. Требования к управлению портфелем проектов», ГОСТ Р 54871-2011 «Проектный менеджмент. Требования к управлению программой».
Таким образом, проект в вузе должен стать «инструментом достижения стратегических целей образовательной организации высшего образования, позволяющий сделать это с минимумом затрат, в кратчайшие сроки» [14]. В результате, проект и проектное управление должно быть отражено в стратегических документах вуза - программах развития университетах, отражающих основные показатели и цели.

Безусловно, управление проектами в университетах имеет свою специфику, которая необходимо учитывать и которая уже подвергалась исследованию в отдельных работах [15].

В предыдущих статьях авторами данного исследования были проанализированы основные внешние факторы, которые способствуют внедрению проектного менеджмента в университете, такие как: изменения в области государственного управления и молодежной политики, реализации национальных проектов, деятельность научных фондов и т.д. [16]. Однако для успешного решения изложенных факторов и трендов вуз должен разработать комплексную программу развития и перейти на проектное управление, которое позволит обеспечить поступательное функционирование и развитие университета.

Для системного анализа программ развития университетов нами были взяты несколько ведущих российских вузов, входящих в «Проект 5-100»: Национальный исследовательский технологический университет НИТУ «МИСиС» (НИТУ «МИСиС»), Уральский федеральный университет имени первого Президента России Б.Н. Ельцина (УрФУ), Балтийский федеральный университет имени Иммануила Канта (БФУ им. И. Канта), Сибирский федеральный университет (СФУ) и Тюменский государственный университет (ТюмГУ). Цель данного проекта - достижение максимальной конкурентоспособности российских вузов в мировом образовательном пространстве, вхождение в число лидеров, среди научнообразовательных центров на глобальном рынке образования. [17].

В программах развития данных университетов основной акцент сделан на образовательные и научные направления. Это вполне объяснимо, т.К. именно эти показатели позволяют вузам занимать лидирующие позиции в различных рейтинговых системах и направлены на основную деятельность высших учебных учреждений. В связи с этим, можно выделить четыре основных блока в программах данных университетов:

- модернизация образовательного процесса;

- модернизация научно-исследовательского процесса и инновационной деятельности;

- развитие кадрового потенциала;

- совершенствование организационной структу- 
Количество проектов, реализуемых вузами, в рамках основных направлений деятельности (по программах развития)

\begin{tabular}{|c|c|c|c|c|c|}
\hline \multirow[b]{2}{*}{ Вуз } & \multicolumn{4}{|c|}{ Количество проектов } & \multirow[b]{2}{*}{$\begin{array}{c}\text { Итого (в процентной } \\
\text { доле по блокам) }\end{array}$} \\
\hline & $\begin{array}{c}\text { модернизация образо- } \\
\text { вательного процесса }\end{array}$ & $\begin{array}{c}\text { модернизация научно- } \\
\text { исследовательского } \\
\text { процесса }\end{array}$ & $\begin{array}{c}\text { развитие кадрового } \\
\text { потенциала }\end{array}$ & $\begin{array}{c}\text { модернизация органи- } \\
\text { зационной структуры } \\
\text { университета }\end{array}$ & \\
\hline НИТУ «МИСиС» & 7 & 6 & 3 & 3 & $\begin{array}{c}19 \\
(37 \% / 31 \% / 16 \% / 16 \%)\end{array}$ \\
\hline УрФу & 5 & 7 & 2 & 2 & $\begin{array}{c}16 \\
(31 \% / 43 \% / 13 \% / 13 \%)\end{array}$ \\
\hline БФУ им. И. Канта & 3 & 5 & 4 & 2 & $\begin{array}{c}14 \\
(22 \% / 36 \% / 28 \% / 14 \%)\end{array}$ \\
\hline СФУ & 7 & 6 & 6 & 5 & $\begin{array}{c}24 \\
(29 \% / 25 \% / 25 \% / 21 \%)\end{array}$ \\
\hline ТюмГУ & 4 & 6 & 5 & 4 & $\begin{array}{c}19 \\
(21 \% / 32 \% / 26 \% / 21)\end{array}$ \\
\hline Итого по 5 вузам & 26 & 30 & 20 & 16 & $\begin{array}{c}92 \\
(28 \% / 33 \% / 22 \% / 17 \%)\end{array}$ \\
\hline
\end{tabular}

ры университета и повышение эффективности управления.

В соответствии с данными направлениями деятельности в программах развития рассматриваемых нами вузов можно выделить количество ключевых проектов и мероприятий, реализуемых университетами, которые представлены в таблице.

Анализ количества и направления проектов показывает, что вузы, как центры образования, в первую очередь, сосредотачивают свое внимание на улучшении образовательного и научно-исследовательского процесса. При этом отметим, что часть проектов и мероприятий среди вузов имеет единую основу, а некоторые из них свою уникальную, специфическую составляющую для данного университета. Исходя из этого, считаем возможным выделить «пул» проектов и мероприятий, которые универсальную составляющую и отвечают требованиям реализации национальных проектов «Образование», «Наука», «Кадры для цифровой экономики» и ежегодному посланию Федеральному собранию Президента РФ.

Анализ программ развития ведущих вузов свидетельствует, что на сегодняшний день в сфере высшего образования приоритетными являются следующие векторы развития:

1. Обеспечение подготовки кадров для базовых отраслей экономики и социальной сферы с переходом к реализации адаптивных, практико-ориентированных и гибких образовательных программ высшего образования, которые обеспечивают получение студентами профессиональных компетенций, отвечающих актуальным требованиям рынка труда, в том числе в области цифровой экономики, командной и проектной работы (Кадры для экономики);

2. Обеспечение возможности для всех категорий граждан к онлайн-курсам, реализуемых организациями и образовательными платформами в соответствии с качеством подготовки обучающихся мировому уровню (Доступность контента мирового уровня);

3. Повышение качества преподавания и соответствие направлений подготовки региональным рынкам труда с учетом мнения работодателей и мониторинга трудоустройства выпускников (Постоянное совершенствование);

4. Решение крупных научно-технологических задач, развития высокотехнологичных отраслей и реализации амбициозных научно-технологических программ (Научно технологические достижения);

5. Внедрение новых образовательных технологий, создание цифрового обучающего контента (симуляторы, виртуальные лаборатории и т. д.), осуществление визуализации учебной информации, а также профессиональная подготовка и переподготовка преподавателей для работы с новыми технологиями (Новые образовательные технологии);

6. Объединение образовательных организаций высшего образования и научных организаций вне зависимости от их ведомственной принадлежности с организациями реального сектора экономики, проводящих научные исследования и разработки мирового уровня (Кооперация).

До сих пор недооценена, роль седьмой задачи - роста экономической устойчивости ООВО. Но именно она 
позволяет добиться стабильности достижений в предыдущих 6 задачах. В то же время, наличие задачи экономической устойчивости и экономической состоятельности достижений в остальных задачах, в условиях ограниченных ресурсов, делает обязательным поиск синергетического эффекта между ними и формирование стратегических проектов, решающих одновременно несколько задач.

В связи с ключевыми задачами развития и проведенным выше анализом ведущих вузов нами были сформулирована универсальная часть программ развития в виде основных проектов, которые должны войти в программы развития вузов, что позволит кардинально изменить всю систему управления, повысить ее эффективность и успешно достигать поставленных целей в будущем.

Важно, что при реализации данных проектов, по нашему мнению, образуется взаимосвязь стратегических задач и ключевых проектов (см. схему), которая позволяет проводить комплексную модернизацию всех составляющих направлений жизнедеятельности университетов с введением показателей целостности и экономической состоятельности.

В соответствии с представленными проектами авторами был проведен анализ проектов, их целеполагание, а также краткое описание, которое представлено ниже.

\section{Проект 1. Внедрение проектного обучения в образовательные программы университета}

Цель проекта - качественное изменение содержания образовательных программ путем введения механизмов проектной деятельности, а также активное вовлечение предприятий реального сектора в процессы формулирования актуальной проблематики проектных заданий, обеспечения доступа к информационным и материальным ресурсам для выполнения работ и оценки результатов работ проектных команд.

Cхема 1

Взаимосвязь стратегических задач и ключевых проектов

\section{Задачи}

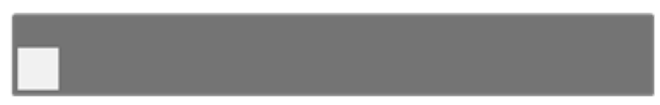

Кадры для экономики

Доступность контента мирового уровня

$\square$ Постоянное совершенствование

$\square \begin{aligned} & \text { Научно технологические } \\ & \text { достижения }\end{aligned}$

$\square$ Новые образовательные технологии

Кооперация

Рост экономической устойчивости

\section{Проекты}

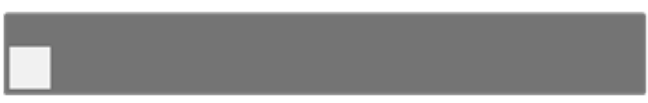

Внедрение проектного обучения

Реализация технологии смешанного обучения; Экспорт образования

Развитие системы отношений с предприятиями реального сектора

Создание научно-образовательных центров

Формирование академической мобильности

Развитие организационной структуры университета Модернизация финансовой и административной системы управления

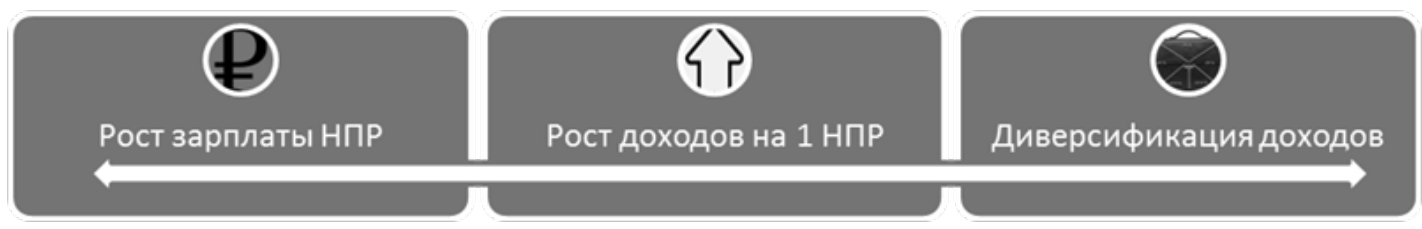

Повышение экономической устойчивости 
В рамках реализации проекта должны быть созданы лаборатории и коворкинги проектного обучения для формирования коммуникационной среды на стыке образования, науки и предпринимательства. Осуществлена качественная модернизация существующих и разработка новых образовательных программ, подготовка руководителей студенческих проектов, сформирована экспертная и партнерская база, внедрена информационная система сопровождения проектной деятельности и взаимодействия с партнерами. Должно быть запланировано применение модели компетенций WorldSkills и элементов индивидуализации образовательных траекторий в качестве механизма повышения мотивации студентов к обучению на основе осознанного выбора и быстрой адаптации траекторий к запросам работодателей.

\section{Проект 2. Реализация технологии смешанного обучения и online-обучения}

Цель проекта - организация совмещения сетевого обучения с очным, интеграция традиционных форм с электронными технологиями.

В рамках данного подхода значительная часть базовых знаний осваивается студентом самостоятельно, а на очных занятиях проходит практическое закрепление материала. Важно, что реализация проекта смешанного обучения позволит не просто дополнить традиционное и уменьшить время, проведенное обучаемыми в аудитории, но и станет неотъемлемой составной частью образовательного процесса, переходящего в новое качественное состояние посредством взаимного влияния и интеграции традиционного и электронного обучения. При этом, по нашему мнению, важно, чтобы практика, проектная и исследовательская работа, занимала не менее 40\% объема общей подготовки специалистов.

При реализации данного проекта важно, что вуз создает базу online-курсов по всем уровням подготовки, что обеспечивает возможность построения индивидуальных образовательных траекторий обучения. В дальнейшем это может послужить экспортом модулей в формирующиеся в России платформы открытого образования, платформы научно-образовательных центров и др.

Масштабное внедрение смешанных технологий обеспечит формирование единого информационного пространства, интегрированного в межвузовское и мировое информационное сообщество, снижение доли аудиторной нагрузки, повышение эффективности образовательных, научно-исследовательских и управленческих процессов.

\section{Проект 3. СозАание научно-образовательных шентров по приоритетным направлениям науки и техники}

Цель данного проекта - ориентирование обучения по приоритетным направлениям науки, а как следствие - организации процесса обучения интегрированного с реализацией исследовательских и прикладных проектов.

Считаем, что отличным примером организации таких центров может стать практика создания проектноучебных лабораторий. Такие лаборатории должны стать одним из механизмов, способствующим повышению практической значимости образовательных программ и обеспечению освоения студентами проектных компетенций через реализацию исследовательских, прикладных и консалтинговых проектов. Важно, что реализация данного проекта позволит обеспечить инфраструктуру для реализации междисциплинарных научных исследований, а также даст возможность закрепления инициативных проектных команд.

Важной особенностью формата проектно-учебных лабораторий является то, что они могут реализовываться как отдельная организационная форма, что дает ряд преимуществ как для коллективов в университете, так и для студентов.

Среди таких преимуществ можно выделить три ключевых:

- проектно-учебные лаборатории обеспечивают инфраструктуру для реализации междисциплинарных проектов;

- статус таких лабораторий позволяет закреплять инициативные проектные команды;

- проектно-учебные лаборатории предоставляют студентам возможность знакомства с принципами работы проектных центров.

\section{Проект 4. Формирование академической мобильности и профессионального роста сотрудников университета}

Цель проекта - обеспечение вуза административным и профессорско-преподавательским составом из числа конкурентоспособных специалистов для решения задач, связанных с достижением поставленных целей. Считаем необходимым разделить данный проект на два взаимосвязанных направления: во-первых, учет и оценка деятельности сотрудников, а во-вторых, создание условий для «взращивания» талантов.

Потребность сегодняшнего дня в том, чтобы переломить склонность профессорско-преподавательского состава считать, что стратегическое планирование осу- 
ществляют и должны осуществлять главные должностные лица (ректор, проректоры), а основная функция ППС ограничивается педагогической деятельностью. Для этого необходима система стимулирования деятельности учебных подразделений университета, при которой краткосрочные результаты оцениваются более существенно, чем усилия, направленные на долгосрочные перспективы развития.

Данное направление проекта позволит предусмотреть ежегодную рейтинговую оценку преподавателей, кафедр и факультетов/институтов (по итогам учебного года) по показателям, характеризующим научную, учебную, методическую и организационную работу. По результатам рейтинговой оценки преподавателям устанавливаются стимулирующие надбавки к должностному окладу. Система рейтинговой оценки в целом позволит повысить эффективность внутреннего контроля и диагностики профессорско-преподавательского состава и кафедр, совершенствовать процесс управления вузом.

Другим направлением должно стать целевая и конкурсная поддержка перспективных студентов-выпускников и молодых преподавателей определенных научных специальностей исходя из текущих и перспективных потребностей вуза путем отбора. Важным условием необходимо предусмотрено отчетность о результатах научно-исследовательской деятельности и эффективности деятельности соискателя. Подпрограммой данного направления может служить формирование так называемого «кадрового резерва» для замещения руководящих должностей путем отбора перспективных сотрудников, обладающих высокими профессиональными и личностными качествами.

\section{Проект 5. Экспорт образования и формирование стратегии межАународного продвижения образовательных услуг}

Цель: повышение привлекательности и конкурентоспособности российского образования на международном рынке образовательных услуг с увеличением роста числа иностранных обучающихся в образовательных организациях.

Проект должен быть направлен на реализацию совместных образовательных программ университета с зарубежными коллегами, а также создание (или расширение) перечня магистерских программ двух дипломов. По нашему мнению, для облегчения процесса интернационализации не менее 30 - 40\% программ магистратуры и аспирантуры должно реализовываться на английском языке.

\section{Проект 6. Развитие системы отношений с преАприятиями реального сектора.}

Цель проекта - развитие научно-технологического сотрудничества с предприятиями реального сектора, в том числе в области инженерных изысканий. Данная инициатива позволит устранить недостаточную системность взаимодействия университета с реальным сектором экономики, увеличить объем заказов на НИОКР.

Основным механизмом должно сопровождения наукоемких и модернизируемых отраслей региона, в том числе через создание в рамках НИЧ функции проактивного поиска заказов на корпоративном рынке, для формирования стратегического партнерства с предприятиями реального сектора экономики. Это позволит создать и оснастить совместно с предприятиями новые лаборатории, в том числе лаборатории центров коллективного пользования, развитие проектных и конструкторских бюро, выполнение прикладных НИР.

\section{Проект 7. Развитие организашионной структуры университета}

Цель: упорядочение организационной структуры и повышение эффективности функционирования вуза в целом.

В части реорганизации существующей структуры управления необходимо:

- четко разделить функции руководителей и существующих структурных подразделений вуза;

- создать отдел по стратегическому развитию и проектному управлению;

- конкретизировать пакеты положений, должностных инструкций и видов работ для операций и процедур, структурных подразделений и рабочих мест.

В структуре управления ответственность за принимаемые решения должна быть сформулирована для каждой должности в виде диапазонов ответственности. В рамках диапазона каждое должностное лицо вуза действует самостоятельно и несет личную ответственность за полученный результат. Одновременно должны быть очерчены деловые отношения, в которые вступают должностные лица между собой для принятия решений, относящихся к их диапазонам ответственности.

В существующую линейно-функциональную структуру может быть встроена матричная структура управления, т.е. введен институт руководителей проектов. Этот статус могут приобретать даже рядовые сотрудники при соответствующей компетентности, выполняющие самостоятельные задания по программе. Это будет способ- 
ствовать более качественному решению проблем, распределению задач, прав и ответственности в системе управления.

\section{Проект 8. Модернизашия финансовой и амминистративной системы управления}

Цель: фокусировка и координация деятельности университета по минимизации финансовых потерь и повышение ответственности не только руководителей структурных подразделений вуза, но и профессорскопреподавательского состава и кафедр за результаты учебной и финансовой деятельности.

На сегодняшний день, очевидно, что изменение современных вузов в сторону «адаптивной профессиональной предпринимательской организации» неизбежный шаг [18]. В связи с этим, одной из задач стратегического управления является придание вузу предпринимательского стиля поведения направленного на повышение доходности вуза за счет непрерывной цепи организационных нововведений. Высшее руководство вуза должно задуматься о совместимости понятий «образование» и «рынок» и предпринять в этом направлении радикальные шаги, необходимость которых обусловлена недостаточным бюджетным финансированием, обострением конкуренции, лавинообразным нарастанием изменением во внешней среде, низкой заработной платой и отсутствием мотивации у профессорско-преподавательского состава и сотрудников. Необходимо разработать концепцию организации внутривузовского предпринимательства, ориентированную на достижение стратегических целей вуза.

Примером таких изменений может стать создание «малых предприятий», цель которых - осуществление научной, производственной и коммерческой деятельности с целью удовлетворения потребностей потребителей и получение на этой основе прибыли. Важно, что спектр и направления деятельности таких предприятий обширен: от проведения научно-исследовательских до ремонтно-строительных работ, оказания услуг в культурно-творческой, спортивной и иной деятельности.

Следующим шагом реализации проекта должно стать внедрение «центров финансовой ответственности» вуза. Каждое структурное подразделение должно рассматриваться как предпринимательская организация, занятая реализацией своего проекта. Таким образом, такие центры получают право самостоятельно распоряжаться полученным доходом и осуществляющая свою деятельность на основе договоров с другими ЦФО, а с другой стороны точечно формируют персональную ответственность за собственное финансовое благополучие, а значит и в целом за вуз.
Результатом проекта должно стать создание центров финансовой ответственности по основным направлениям деятельности университета, формирование единой системы бухгалтерского и налогового учета движения финансовых средств, расширение технологий электронных услуг, оптимизация основных бизнес-процессов с целью эффективного управления ресурсами университета.

Реализация данных проектов является для вузов амбициозной и долговременной задачей. Однако университет является сложной системой, где глобальные изменения требуют тщательной подготовки, детального планирования и готовности вкладывать большие ресурсы в течение длительного времени для получения отсроченных результатов в стратегической перспективе. В результате, преимущества проектного управления входят в противоречия, расхожие в академической среде.

Основная проблема управления в вузе заключается в том, что традиционные методы организации не предполагают проектное управление. Взаимодействие идет по линии операционной деятельности: «проректор управление - отдел», либо «проректор - дирекция (деканат) - кафедра». При этом отсутствуют нормативные и регулирующие отношения проектного управления в самой организации. Даже при внешней декларативности о переходе ведущих университетов на проектный менеджмент в программах развития вузов об этом мало упоминается. Так, среди указанных нами выше вузов только в стратегических целях и показателях ТюмГУ можно найти то, что университет к 2018-2020 гг. планирует полный переход на проектное управление. По нашему мнению, Департамент проектной деятельности Министерства науки и высшего образования должен взять на себя функции методического центра и разработать рекомендации для вузов по поэтапному переходу к проектному управлению.

Следующим вопросом становится готовность самой корпоративной культуры вуза и сотрудников в целом к новым способам управления. Ни для кого не секрет, что любые изменения воспринимаются рядовыми работниками как «чуждые насаждения сверху». Дополняется это практически отсутствием квалифицированного персонала с проектными компетенциями. Так, только не более 150 человек в сфере высшего отечественного образования являются сертифицированными специалистами (по сведениям Российской ассоциации управления проектами «Совнет»), которые прошли обучение по управлению проектами по стандарту ICB IPMA. В рамках других систем обучения и стандартов количество почти не отличается. Поэтому руководителям вузов нужно быть готовым к тому, что первоначально проектное управление приведет к видимым затратам и лишь в перспективе экономии средств и ресурсов. 
В связи с этим, для решения вышеназванных задач в каждом конкретном вузе должен быть разработаны комплексные проекты с четко сформулированными количественными результатами, экономической моделью, а также выраженной и ориентированной во времени целью. Цель проекта подразделяется на мероприятия, что должно трансформироваться в задачи структурных подразделений университета, быть отражено в индивидуальных КРI (Key Performance Indicators) сотрудников.

Считаем, что планомерное внедрение вышеизложенных рекомендаций по применению инструментов проектного управления, в рамках реализации программ развития, позволит сформировать организационную культуру работы с проектами, применять на практике программно-аналитические средства и повышать эффективность образовательной деятельности вуза. Кроме того, внедрение проектного подхода в деятельность университетов может стать ключевым методом при достижении тактических и стратегических целей инновационного развития вуза, позволяющих достигать инициируемых и целенаправленных трансформаций в относительно короткие сроки и отвечающих таким принципам организации современного образовательного пространства, как прагматичность, открытость, постоянное развитие, системность и прозрачность.

\section{ЛИТЕРАТУРА}

1. Паспорт Национального проект «0бразование». [Электронный ресурс]. - URL: http://government.ru/info/35566/ (дата обращения: 15.08.2020).

2. Программа стратегического академического лидерства [Электронный ресурс]. - URL: https://www.minobrnauki.gov.ru/ru/press-center/card/?id_4=2875 (дата обращения: 15.08.2020).

3. Юсупов В.З. Источники, методологические основы и понятийный аппарат проектного управления в педагогическом менеджменте // Научные труды Московского гуманитарного университета. - 2018. - № 4. - С. 15 - 43.

4. Герасикова Е.Н. Проектное обучение в действии: опыт реализации проектного подхода в подготовке будущих специалистов Калужской области // Экономика и современный менеджмент: теория и практика: сб. ст. по матер. XLVII междунар. науч.-практ. конф. - Новосибирск: СибАК, 2015. - №3(47). C. 26-31.

5. Завьялова Н.Б., Сагинова О.В. Проектная работа студентов: как улучшить результат// Креативная экономика. - 2017. - №9 - Т. 11. - С. $943-952$.

6. Завьялова Н.Б., Сагинова О.В. Проектная работа студентов // Плехановский научный бюллетень. - 2018. - №1. - С. 35-37.

7. Завьялова Н.Б., Сагинова 0.В., Стукалова А.А., Максимова С.М. Место и роль проектной работы в подготовке специалистов для современной экономики // Российское предпринимательство. - 2017. - Т. 18. - №19 - С. 2759-2768.

8. Сагинова 0.В., Гришина 0.А., Штыхно Д.А. Проектное обучение студентов на основе заказов малых и средних предпринимательских структур // Российское предпринимательств0. - 2017. - Т. 18. - №3. - С. 417-425.

9. Дульзон А.А. Опыт обучения управлению проектами // Высшее образование в России. - 2013. - № 10. - С. 83-90.

10. Сауренко Н.Е. Управление проектами в высшей школе // Мир науки, культуры, образования. - 2011. - № 5. - С. 195-198.

11. Бабенко Е.И., Загороднова Е.П. Проектная деятельность университета на основе стратегического анализа // ARS ADMINISTRANDI. 2011. № 4. C. 29-35.

12. Москвин С.Н. Управление проектами в сфере образования. Учебное пособие для вузов. - М.: Издательство Юрайт, - 2019. - 139 с.

13. Управление проектами / И.И. Мазур, В.Д. Шапиро, Н.Г. Ольдерогге, А.В. Полковников. - М., 2010. -960 с.

14. Полевой С.А., Чалова А.В. Проблемные вопросы проектной деятельности в организациях высшего образования // Проблемы современного образования. $-2019 .-$ С. $136-143$.

15. Проектное управление научной деятельностью вуза. Методический инструментарий: монография // под ред. д-ра экон. наук, проф. А.В. Шишкина. М.: Издательство «Палеотип». - 2013. - 144 с.

16. Сандлер Д.Г., Островкин Д.Л. Формирование инструментов проектного управления в системе высшего образования // Вестник БИСТ. Серия «Экономика». - № 1 (46), -2020 . - С. $24-35$.

17. Подробнее на сайте Проекта 5-100. [Электронный ресурc]. - URL: https://www.5top100.ru (дата обращения 10.08.2020).

18. Грудзинский А.О. Стратегическое управление университетом: от плана к инновационной миссии // Университетское управление: практика и анализ. 2004. - № 1. - C. $9-20$.

() Сандлер Даниил Геннадьевич (d.g.sandler@urfu.ru), Островкин Денис Леонидович (ostrovkin.denis@yandex.ru). 